\title{
Effect of Self-Expanding Carotid Stents on Plaque Thickness and Vessel Diameter
}

\author{
Rafael Martínez-Pérez, Graeme Marchuk, Donald H. Lee, David M. Pelz, \\ Stephen P. Lownie
}

\begin{abstract}
Background: In vitro models have suggested that stents affect atherosclerotic plaques symmetrically because of their outward radial forces. We evaluated the effects of stents on carotid plaque and the arterial wall using carotid ultrasound in carotid stenting patients to see whether these effects were borne out in vivo. Methods: From a carotid stent database, 30 consecutive patients were selected. All had carotid Doppler ultrasound performed pre- and poststenting. The diameters of the lumen at the level of stenotic plaque pre- and poststenting, the dorsal and ventral plaque thickness, and of the outer arterial wall diameter were measured. Plaque thickness was measured at the level of maximal stenosis. Nonparametric tests were used to determine whether the stent effect and luminal enlargement were based on wall remodeling or on total arterial expansion. Results: The patients were followed for an average of 22 months. Eighteen patients were male, with an average age of 70 years. A total of $87 \%$ of patients were symptomatic ipsilateral to the side of stenosis. Nine patients had angioplasty intraprocedurally. The luminal diameter increased poststenting in the region of severe stenosis. Plaque thickness, both ventrally and dorsally, decreased poststenting, with no significant difference between the ventral and dorsal plaque effects. The outer arterial wall diameters did not change. The measured lumen in the stent increased over time poststenting. Conclusions: Self-expanding nitinol stents alter the baseline ventral and dorsal plaque to a significant degree and do not significantly affect the native arterial wall and the overall arterial diameter.
\end{abstract}

RÉSUMÉ: L'effet des endoprothèses auto-expansibles sur l'épaisseur des plaques arthéroscléreuses de l'artère carotide et sur son diamètre. Contexte: Des modèles in vitro suggèrent que les endoprothèses, en raison de leur force radiale extérieure, affectent les plaques d'arthérosclérose de façon symétrique. Au moyen d'une échographie, nous avons voulu évaluer les effets in vivo de ce type de prothèses sur les plaques arthéroscléreuses de l'artère carotide et sur sa paroi artérielle. Méthodes: Nous avons choisi 30 patients de façon consécutive à partir d'une base de données constituée d'individus à qui l'on avait posé une endoprothèse à l'intérieur de leur artère carotide. Tous avaient bénéficié d'une échographie Doppler avant et après la pose d'une telle prothèse. Nous avons du coup mesuré le diamètre des lumières au niveau des plaques arthéroscléreuses avant et après cette pose. Nous avons aussi mesuré l'épaisseur de ces plaques en lien avec les faces ventrale et dorsale de la carotide ainsi que le diamètre de la paroi artérielle extérieure de cette artère. L'épaisseur des plaques a été mesurée en fonction du niveau maximal de sténose. Nous avons également fait appel à des tests non paramétriques afin de déterminer dans quelle mesure l'effet des endoprothèses et l'élargissement des lumières pouvaient être attribués à un remodelage de la paroi artérielle ou à une expansion totale de la pression artérielle. Résultats: En moyenne, les patients, dont l'âge moyen avoisinait les 70 ans, ont été suivis pendant 22 mois. Dix-huit d'entre eux étaient des hommes. $87 \%$ des patients montraient des symptômes ipsilatéraux du côté de la sténose. Neuf patients avaient subi une angioplastie en même temps que la pose d'une endoprothèse. À la suite de cette pose, le diamètre des lumières s'est accru dans les parties montrant une sténose aiguë. L'épaisseur des plaques des faces ventrale et dorsale de l'artère carotide a également diminué, aucune différence notable n'ayant été observée en ce qui concerne les effets sur les unes ou sur les autres. De plus, le diamètre de la paroi artérielle extérieure est resté le même. Enfin, les lumières mesurées dans les endoprothèses ont augmenté au fil du temps. Conclusions: Les endoprothèses auto-expansibles en nickel-titane (nitinol) modifient dans une large mesure les plaques des faces ventrale et dorsale de l'artère carotide. Cela dit, elles n'affectent pas de façon notable sa paroi artérielle originelle ainsi que son diamètre total.

Keywords: carotid stenosis, stent, carotid artery

doi:10.1017/cjn.2016.459

Can J Neurol Sci. 2017; 44: 498-502

Carotid stenosis is responsible for up to $20 \%$ of strokes in the adult population. ${ }^{1}$ Carotid artery stenting has been shown to be an effective and safe alternative to carotid endarterectomy, especially in patients at high risk for surgery. ${ }^{2,3}$

There is uncertainty about how stents actually remodel plaque and how they affect arterial diameters. ${ }^{4}$ Although numerous studies have reported an improvement in flow and an increase in luminal diameter poststenting, ${ }^{5-8}$ there is a lack of information about the relative effects of stent self-expansion on the plaque itself and the native arterial wall.
The purpose of this prospective study is to evaluate the relative effects of self-expanding nitinol stents on plaque remodeling and

From the Departments of Clinical Neurological Sciences (RMP, GM, SPL) and; Medical Imaging (DHL, DMP), Schulich School of Medicine and Dentistry, Western University, London, Canada.

Received April 15, 2016. Final Revisions Submitted November 7, 2016 Date of ACCEPTANCE November 11, 2016.

Correspondence to: Rafael Martinez-Perez, Department of Clinical Neurological Sciences, Division of Neurosurgery, London Health Science Centre, 339 Windermere Road, London, ON N6A 5A5, Canada. Email: rafa11safin@ hotmail.com 
lumen and vessel diameter by analyzing pre- and postoperative carotid Doppler sonography (CDS) in stented patients.

\section{Materials AND Methods}

\section{Study Population}

Between January 2006 and January 2008, 32 patients were selected from a prospectively maintained database of 136 patients for analysis based on the following criteria.

- Carotid artery stenting performed for either symptomatic carotid stenosis or high grade of asymptomatic $(>70 \%$ based on North American Symptomatic Carotid Endarterectomy Trial [NASCET] criteria) stenosis in the setting of a clinical trial. ${ }^{9}$

- Pre- and postprocedural CDS available for the study.

- Patients with poor quality CDS images (vessel too deep for adequate insonation or extensive calcified plaque obscuring the lumen) were not included in the analysis.

\section{Carotid Stenting Procedure}

Patients were taking dual antiplatelet medication for at least 3 days before the intervention (either acetylsalicylic acid or clopidogrel); this was continued up to the time of the intervention. Clopidogrel was discontinued at 6 weeks of follow-up, whereas acetylsalicylic acid was continued indefinitely. The procedure was performed according to our previously published protocol. ${ }^{5}$ The stenosis was crossed with an 8-mm-diameter $\mathrm{x}$ 40-mm-length self-expanding stent, either with Acculink (Abbott) in $20 \%$ of cases, or Precise stent (Cordis) in $80 \%$ of cases. According to our previous experience, ${ }^{5}$ balloon assistance was used only when necessary to initially cross a severe stenosis with the stent, or if a significant stenosis remained after deployment of the stent, usually resulting from a circumferential plaque calcification. Distal protection devices can add risk to the procedure ${ }^{10}$ and are not included in our routine treatment protocol. Following stent deployment, angiographic views of the neck and head were obtained. The heparinization was allowed to gradually wear off.

\section{Radiological Assessment}

The degree of stenosis before stent deployment was quantitated using the NASCET criteria. ${ }^{9}$ Follow-up assessment was done with periodic CDS. These studies were carried out within 1 week of the procedure, then once or twice in the next 6 months, once again during the next 12 months, and every 6 months or annually thereafter. The effect on carotid remodeling was assessed by comparing the preprocedural results and the last follow-up results available.

\section{CDS Measurements}

All measurements were assessed by a neuroradiologist not involved in the stent deployment (DHL). For better evaluation of the remodeling effects of internal carotid artery (ICA) stenting, the CDS examinations were performed using the same machine. A two-dimensional ultrasound system, equipped with a $10-\mathrm{MHz}$ scanning frequency in real-time B-mode and $6 \mathrm{MHz}$ scanning frequency in pulsed Doppler mode, was used. The examination included the longitudinal view of the affected extra cranial carotid artery. These were chosen rather than transverse planes to better assess the region of plaque. Total vessel diameter and ventral plaque and dorsal plaque thickness were assessed using the real-time B-mode at the most stenotic site (Figure 1). The middle, proximal, and distal diameters were assessed using the color-coded flow imaging in the Doppler mode (Figure 2).

\section{Statistical Methods}

Statistical analysis was performed using SPSS 20.0. Testing was done using analysis of variance (ANOVA) and Student $t$ test distribution for paired samples. A two-tailed $\mathrm{p}$ value $<.05$ was considered significant.

\section{Results}

Thirty-two patients were initially included in the study. After reviewing the ultrasound images, two patients were excluded for having heavy calcified plaques. Of the 30 individuals studied, 18 men and 12 women with an average age of 70 years (range, 54-91) were included. Thirteen percent of the patients were asymptomatic and $87 \%$ had symptoms related to the site of the stenosis. Symptoms included 17 patients with transient ischemic attacks, eight with stroke, and one with amaurosis fugax. Five patients had moderate stenosis; the remainder had severe stenosis. Mean of degree of stenosis, according to NASCET criteria, ${ }^{9}$ was $77.2 \%$ preprocedure and $39.7 \%$ after the main procedure.

Nine patients had intraprocedural angioplasty; two had prestent angioplasty and seven had angioplasty poststent stent deployment. No protective devices were used in any patient. Pairwise comparison testing did not show significant differences in terms of lumen diameter, vessel diameter, or plaque thickness between those patients additionally treated with angioplasty and those who received the self-expandable stent without pre- or postangioplasty $(\mathrm{p}>0.05)$.

None of the patients who received the self-expandable stent without additional angioplasty experienced any direct complication derived from the procedure or new neurological deficits.

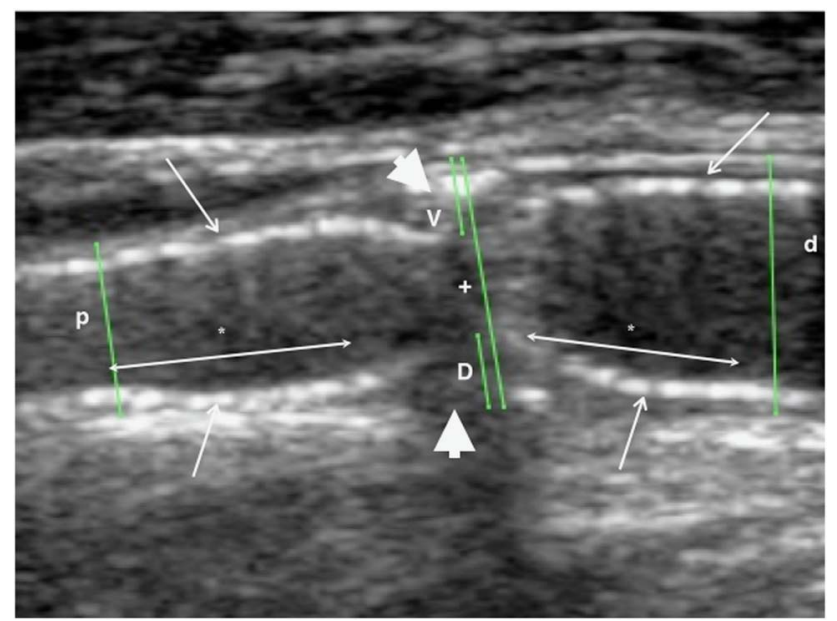

Figure 1: Follow-up representative B-mode ultrasound from patient 11 in our series detailing the measurements obtained for statistical analysis. The stent (white arrows) is visualized as a hyperecogenous signal in the periphery of the vessel. The proximal ( $p)$ and distal diameter $(d)$ of the vessel is measured at $1 \mathrm{~cm}$ from the plaque edge, as shown in the image (*) in millimeters. The ventral (v) and dorsal (d) plaque thickness and mid-vessel diameter (+) are measured in millimeters at the midpoint of the plaque (arrowhead). 


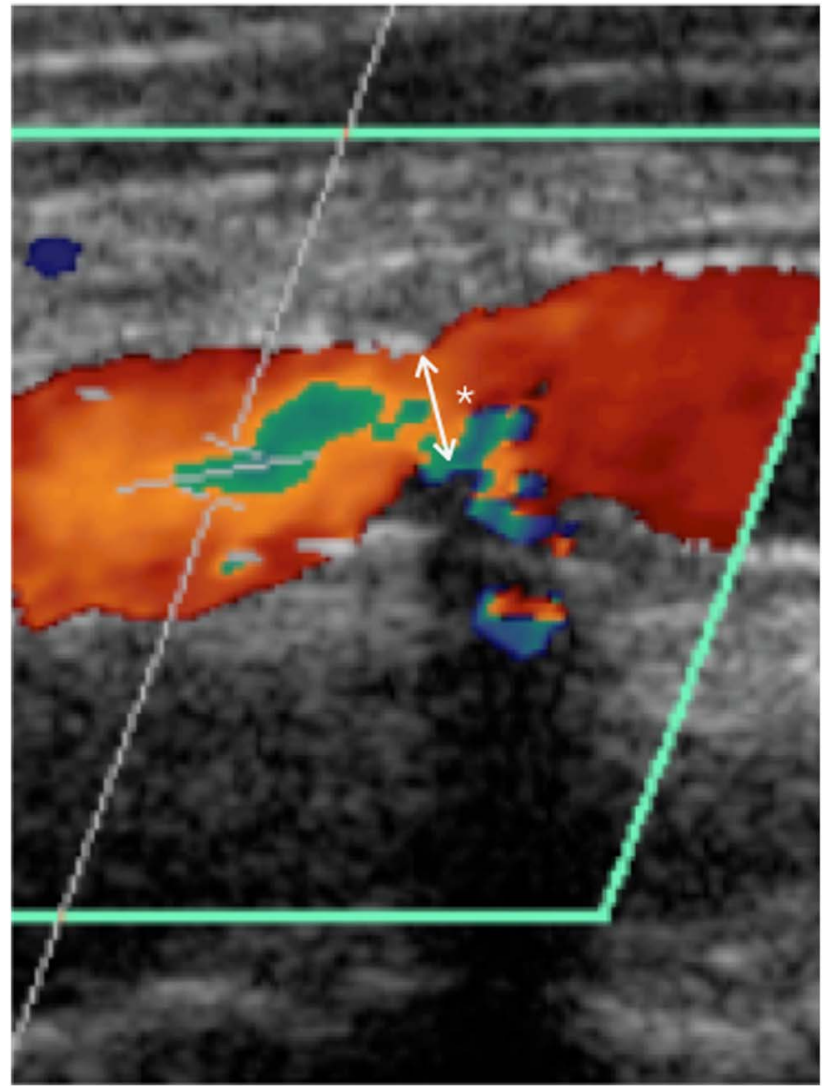

Figure 2: Color Doppler image of the same patient, which was used to obtain the luminal diameter. Three-dimensional color Doppler ultrasound, sagittal view. Red=blood flow. *Luminal diameter measured in millimeters at the most stenosed segment.

One of the patients treated with postprocedural angioplasty had an auto-limited episode of 20 minutes of amaurosis fugax. It was managed conservatively and the patient recovered to his baseline state.

Paired results of pre- and postprocedure angiography were available in all 30 patients. Average follow-up was 22 months (range, 1-50 months). Eight patients had less than 1-year of follow-up. Changes in vessel diameter, lumen diameter, and plaque thickness during the follow up are represented in Figure 3.

The changes in CDS parameters between the prestent studies and last follow-up are listed in Table 1. Significant differences poststenting occurred for the plaque morphology (either ventral or dorsal) and luminal measurements, but not for the proximal, mid, or distal outer arterial vessel diameter.

Pairwise comparison testing indicates no difference in stent expansion in terms of its effect on the ventral and dorsal plaque (i.e. they each remodel to an equal degree; $\mathrm{p}>0.05$ ).

\section{DISCUSSION}

Carotid stents can expand for up to 6 months after the procedure. ${ }^{5,6,11}$. This finding is confirmed in the present study, showing an average diameter increase of more than $2 \mathrm{~mm}$ over an average follow-up of 22 months. However, little is known about the relative effect of the stent on plaque thickness compared with overall expansion of the external arterial wall. In vitro experimental studies

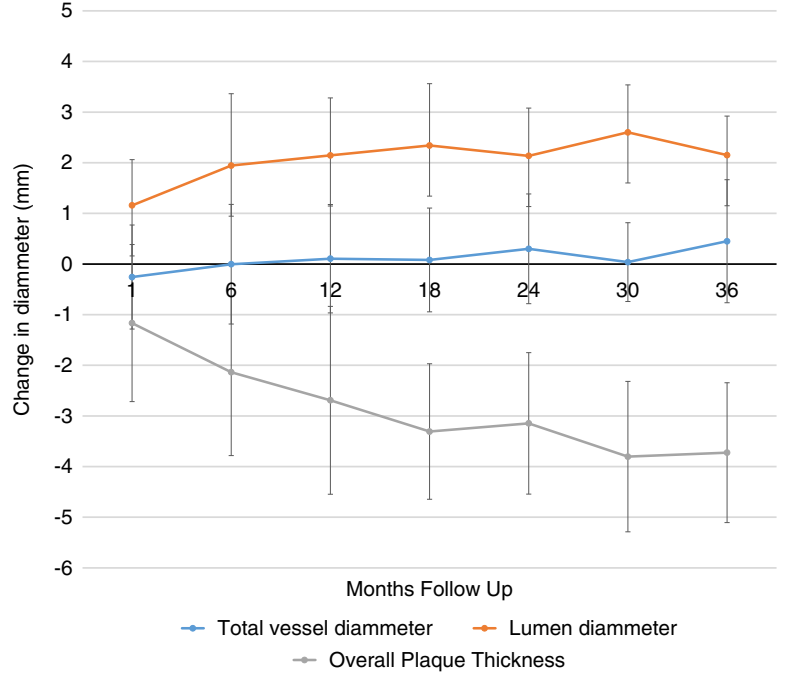

Figure 3: CDS measurements along the study follow-up.

based on the use of rigid polytetrafluoroethylene stents have suggested that stents affect plaques symmetrically because of radial effects, ${ }^{4,12}$ but this finding has not yet been shown in humans.

Our major findings were as follows: (1) self-expanding nitinol stents alter the baseline ventral and dorsal plaque thickness to a significant degree, while not significantly affecting the native arterial wall; and (2) stenting appears to impact the ventral and dorsal components of the plaque equally, which would be expected given their radial expansion. ${ }^{13,14}$

Our results suggest that an increase in luminal diameter is achieved by a process of plaque remodeling and is not accompanied by native arterial expansion. The radial outward force produced by a self-expanding stent compresses the plaque component in all directions in a similar manner, but this force is not enough to produce a dilatation of the arterial wall, avoiding the risk of vessel rupture. No previous investigators have looked at changes in outer vessel wall diameter, although there have been reports of vessel wall rupture with subsequent hematoma and pseudo aneurysm formation. ${ }^{15,16}$ It is unclear whether these complications were due to balloon expansion, by the stent, or by a combination of both. It is well-known that artery wall disruption and other complications are much more common in angioplasty

Table 1: Mean difference \pm SD for each of the 6 measured values between the baseline (i.e. pretreatment) and final poststent ultrasound

\begin{tabular}{l|c|l|c}
\hline Parameter & Changes in diameter $(\mathbf{m m})$ & SD & Significance \\
\hline Mid-vessel diameter & -0.12 & 1.33 & $\mathrm{p}=0.448$ \\
\hline Proximal vessel diameter & -0.037 & 0.897 & $\mathrm{p}=0.898$ \\
\hline Distal vessel diameter & +0.2 & 1.076 & $\mathrm{p}=0454$ \\
\hline Ventral plaque thickness & -1.55 & 1.13 & $\mathrm{p}<0.01$ \\
\hline Dorsal plaque thickness & -1.34 & 1.1 & $\mathrm{p}=0.01$ \\
\hline Luminal diameter & +2.13 & 1.37 & $\mathrm{p}<0.01$ \\
\hline
\end{tabular}

$\mathrm{p}$ values demonstrate the results of paired $t$ test and repeated measures ANOVA analysis of the baseline and final poststent measurements. 
with angioplasty balloons and balloon expandable stents than with self-expanding stents alone. ${ }^{17,18}$ This is a potential benefit of selfexpanding stents over balloon-expandable stents. Self-expanding stents gradually reduce the stenosis over time, without inducing changes in the external arterial wall, reducing rupture risk. There is good evidence that arterial injury with both balloons and stents leads to an inflammatory response and activates a proliferative repair process, the end result of which can lead to luminal narrowing and in-stent restenosis. ${ }^{6,11,19,20}$ These results could not be confirmed in our study, but this could be influenced by small size of the sample. Avoidance or limitation of arterial injury associated with balloon inflation may also be beneficial in minimizing such restenosis. ${ }^{17,21}$ It is believed that balloon distention of the carotid sinus is responsible for hemodynamic depression intra- or postoperatively. ${ }^{22,23}$ The use of selfexpanding stents alone can minimize this risk. ${ }^{24}$

The acceptable reproducibility and interobserver reliability of the measurements of the plaque thickness and lumen diameter has been previously reported. ${ }^{6}$

Limitations of this study include metallic artifact produced by the stent, which can underestimate the real value of the lumen diameter on CDS.

Several papers ${ }^{6,11}$ have remarked that neointimal proliferation prevails at an early stage, up to 12 months, which corresponds to the period of maximal stent expansion. Rarely, this can result in early restenosis. Later on, the neointimal proliferation remains stable and positive remodeling gains prominence. In our series, $26 \%$ of patients examined were followed for less than 1 year, and the degree of intimal remodeling may be underestimated.

Use of CDS has some limitations. Plaque with dense calcification, a carotid bifurcation with marked tortuosity, and a high cervical stenosis may not be adequately imaged. ${ }^{9}$ Two of our patients had to be excluded from the study for having heavy calcified plaques.

Our two-dimensional carotid Doppler date demonstrates changes in ventral and dorsal plaque thickness, without significant differences in thickness between dorsal and ventral. A three-dimensional radiological diagnostic method, such a high-resolution computed tomography scan would confirm whether this changes truly occur equally in all the plaque in vivo, particularly in areas of heavy calcification.

\section{ConClusions}

The plaque is remodeled by the outward radial force produced by the self-expandable stents, without producing changes in diameter by expanding the external carotid wall, Stenting appears to impact the ventral and dorsal components of the plaque equally, which would be expected given their proposed method of radial expansion.

\section{ACKNOWLEDGMENTS AND FUNDING}

The authors have no source of funding relative to the research or elaboration of this work.

\section{Disclosures}

RPM has received research support from the Fundacion Alfonso Martin Escudero, Madrid, Spain, for his fellowship at Western University. The remaining authors do not have any disclosures.

\section{REFERENCES}

1. Linfante I, Andreone V, Akkawi N, Wakhloo AK. Internal carotid artery stenting in patients over 80 years of age: single-center experience and review of the literature. J Neuroimaging. 2009;19:158-63.

2. Mas JL, Chatellier G, Beyssen B, et al. Endarterectomy versus stenting in patients with symptomatic severe carotid stenosis. N Engl J Med. 2006;355:1660-71.

3. Mantese VA, Timaran CH, Chiu D, Begg RJ, Brott TG. The Carotid Revascularization Endarterectomy versus Stenting Trial (CREST): stenting versus carotid endarterectomy for carotid disease. Stroke. 2010;41(10 Suppl):S31-4.

4. Benndorf G, Ionescu M, Alvarado YMV, Hipp J, Metcalfe R. Wall shear stress in intracranial self-expanding stents studied using ultra-high-resolution 3D reconstructions. AJNR Am J Neuroradiol. 2009;30:479-86.

5. Lownie SP, Pelz DM, Lee DH, Men S, Gulka I, Kalapos P. Efficacy of treatment of severe carotid bifurcation stenosis by using selfexpanding stents without deliberate use of angioplasty balloons. AJNR Am J Neuroradiol. 2005;26:1241-8.

6. Willfort-Ehringer A, Ahmadi R, Gruber D, et al. Arterial remodeling and hemodynamics in carotid stents: a prospective duplex ultrasound study over 2 years. J Vasc Surg. 2004;39:728-34.

7. Puato M, Piergentili $\mathrm{C}$, Zanardo $\mathrm{M}$, et al. Vascular remodeling after carotid artery stenting. Angiology. 2007;58:565-71.

8. Coward LJ, Featherstone RL, Brown MM. Safety and efficacy of endovascular treatment of carotid artery stenosis compared with carotid endarterectomy: a Cochrane systematic review of the randomized evidence. Stroke. 2005;36:905-11.

9. Beneficial effect of carotid endarterectomy in symptomatic patients with high-grade carotid stenosis. N Engl J Med. 1991;325:445-53.

10. Cremonesi A, Manetti R, Setacci F, Setacci C, Castriota F. Protected carotid stenting: clinical advantages and complications of embolic protection devices in 442 consecutive patients. Stroke. 2003;34:1936-41.

11. Clark DJ, Lessio S, O'Donoghue M, Tsalamandris C, Schainfeld R, Rosenfield K. Mechanisms and predictors of carotid artery stent restenosis: a serial intravascular ultrasound study. J Am Coll Cardiol. 2006;47:2390-6.

12. Mohr A, Wenke R, Roemer FW, et al. Micro-CT of carotid arteries: a tool for experimental studies. Cardiovasc Intervent Radiol. 2004;27:651-4.

13. Voute MT, Hendriks JM, van Laanen JH, et al. Radial force measurements in carotid stents: influence of stent design and length of the lesion. J Vasc Interv Radiol. 2011;22:661-6.

14. Ghriallais RN, Bruzzi M. Self-expanding stent modelling and radial force accuracy. Comput Methods Biomech Biomed Engin. 2014;17:318-33.

15. Stirling MJ, Smith TP, McCann RL. Carotid artery angioplasty and stent placement: postprocedural hemorrhage and delayed pseudoaneurysm formation. J Vasc Interv Radiol. 2008;19:595-9.

16. Broadbent LP, Moran CJ, Cross DT, 3rd, Derdeyn CP. Management of ruptures complicating angioplasty and stenting of supraaortic arteries: report of two cases and a review of the literature. AJNR Am J Neuroradiol. 2003;24:2057-61.

17. Rosenkranz M, Eckert B, Niesen WD, Weiller C, Sliwka U. Horner syndrome related to ipsilateral carotid wall hematoma after stent placement for the treatment of carotid stenoses. AJNR Am J Neuroradiol. 2003;24:1508-11.

18. Dieter RS, Ikram S, Satler LF, Babrowicz JC, Reddy B, Laird JR. Perforation complicating carotid artery stenting: the use of a covered stent. Catheter Cardiovasc Interv. 2006;67:972-5.

19. Farb A, John M, Acampado E, Kolodgie FD, Prescott MF, Virmani R. Oral everolimus inhibits in-stent neointimal growth. Circulation. 2002;106:2379-84.

20. Barth KH. Prototype stent in canine iliac arteries. J Vasc Interv Radiol. 1996;7:948-9.

21. von Birgelen C, Kutryk MJ, Serruys PW. Three-dimensional intravascular ultrasound analysis of coronary stent deployment and in-stent neointimal volume: current clinical practice and the concepts of TRAPIST, ERASER, and ITALICS. J Invasive Cardiol. 1998;10:17-26. 
22. Qazi U, Obeid TE, Enwerem N, et al. The effect of ballooning following carotid stent deployment on hemodynamic stability. J Vasc Surg. 2014;59:756-60.

23. Leisch F, Kerschner K, Hofmann R, et al. Carotid sinus reactions during carotid artery stenting: predictors, incidence, and influence on clinical outcome. Catheter Cardiovasc Interv. 2003;58:516-23.

24. Bussiere M, Pelz DM, Kalapos P, et al. Results using a selfexpanding stent alone in the treatment of severe symptomatic carotid bifurcation stenosis. J Neurosurg. 2008;109:454-60. 